ISSN: $1130-2887$

DOI: http://dx.doi.org/10.14201/alh2014683955

\title{
OCUPANTES, CASAS OCUPADAS Y LA ESFERA RESIDENCIAL DE LOS «POBRES URBANOS» EN LA CIUDAD DE BUENOS AIRES
}

Squatters, Squatted houses and Residential Area of the «urban poor» in the city of Buenos Aires

\author{
Natalia VERÓN \\ Universidad Nacional de Lomas, Argentina \\ 凶nataliaveron@gmail.com
}

BIBLID [1130-2887 (2014) 68, 39-55]

Fecha de recepción: 3 de junio del 2014

Fecha de aceptación y versión final: 15 de octubre del 2014

RESUMEN: Las ocupaciones de inmuebles abandonados por parte de habitantes de escasos recursos expresan una práctica residencial característica de los barrios del centro y sur de la ciudad de Buenos Aires. Desde una perspectiva etnográfica se analiza la diversidad de normas sociales involucradas en las prácticas de acceso a cuartos en una ocupación histórica de la ciudad. Se discuten los alcances del concepto de mercado informal en el análisis de las prácticas de intercambio económico que rigen en esta esfera residencial.

Palabras clave: casas tomadas; Buenos Aires; etnografía; mercado informal; segregación residencial.

ABSTRACT: The aim of this paper is to analyze the diversity of social norms involves in housing occupation from an ethographic perspective. Since the occupation of abandoned property is a common practice among people of low income especially in central and southern neighborhoods of Buenos Aires, the article focuses and discuss the scope of the concept of informal market through the study of the governing economic exchange in those residentials areas.

Key words: squattes; Buenos Aires city; ethnography; informal market; residential segregation. 


\section{INTRODUCCIÓN ${ }^{1}$}

Las ocupaciones de inmuebles abandonados por parte de habitantes de escasos recursos expresan una práctica residencial característica de los barrios del centro y sur de la Ciudad Autónoma de Buenos Aires (CABA). Durante la década de 1980, en el marco de la apertura democrática que puso fin al gobierno autoritario que gobernó el país entre 1976 y 1983, las ocupaciones inauguraron el retorno de los sectores populares, expulsados por la política urbana militar. Hoy en día esta modalidad habitacional es cuestionada desde un discurso que estigmatiza a los ocupantes y sitúa su práctica en la esfera de lo delictivo. La reforma del código penal en 1994, puntualmente la introducción de la figura del desalojo inmediato y de la clandestinidad e invasion para sancionar penalmente a los ocupantes da cuenta de este giro en la política estatal en relación a las ocupaciones.

En este artículo se analizan las prácticas sociales de acceso a cuartos de casas tomadas de un grupo de habitantes de una antigua ocupación del barrio de Balvanera, en la CABA. Desde una perspectiva etnográfica, se abordan las diversas normas que rigen la vida cotidiana dentro de esta casa y las respectivas valorizaciones de sus habitantes relativas a su residencia en esta modalidad del hábitat popular. En el marco del presente análisis, se recurre a un conjunto de teorías sobre mercados informales de tierra y vivienda que analizan los procesos de mercantilización que durante las últimas dos décadas pautaron las formas e acceso a viviendas en villas, asentamientos y favelas, entre otras modalidades del hábitat popular características de las ciudades latinoamericanas (Cravino 2006, Abramo 1998, 2003, Smolka 2003, Duhau 2003).

Lejos de las tradicionales ocupaciones y loteos (Clivchevsky y Herzer 1990, Clivchevsky 2000) y diversos en su funcionamiento estos mercados se montan sobre la complejización y densificación de procesos de segregación urbana en las áreas metropolitanas introduciendo modalidades novedosas de acceso a la tierra. Como analiza la antropóloga María Cristina Cravino, un mercado informal se configura en las villas de la ciudad, donde el acceso a la tierra de forma desmercantilizada, a través de relaciones de reciprocidad local, parece ser un recurso agotado. Con la configuración de este mercado se establecen un conjunto de normas de cara a las transacciones inmobiliarias que invariablemente asignan valor a los bienes existentes en su interior. No obstante, la mercantilización del acceso a inmuebles en villas se incrusta en formas sociales que surgieron de manera no mercantilizada (Cravino 2006).

El enfoque anterior permite identificar los contornos de un conjunto de transacciones entabladas al interior de casas tomadas, además de observar la emergencia de un cuerpo de normas tácitas que pautan a las primeras. Las formas mercantilizadas o desmercantilizadas de acceso a los cuartos lejos de ser uniformes (y constituyentes del campo en cuestión como un submercado) se evidencian desigualmente en diversos contextos (en las casas tomadas, en organizaciones sociales y en instituciones públicas)

1. La autora agradece los comentarios y sugerencias de dos evaluadores anónimos de América Latina Hoy, Revista de Ciencias Sociales a una primera versión de este artículo. 
precisamente por estar permeadas por diversos valores morales en torno a las prácticas habitacionales de los pobres urbanos y a sus modalidades de socialización. Prácticas sociales como las de vender, comprar y ocupar convocan, en distintos contextos sociales, valores morales contrastantes, observables en las preferencias, deseos y obligaciones (Pitt-Rivers 1989) asumidos por las personas a la hora de optar por determinado ámbito de residencial. Conjuntamente, debido a que las trayectorias residenciales de quienes habitan en casas tomadas trascienden este nicho del mercado informal, sus concepciones y valorizaciones en torno a la residencia se alimentan de normatividades ajenas a este espacio.

Por estos motivos, se considera que el concepto de «mercado informal» permite delinear la existencia de un conjunto de prácticas económicas y normatividades que rigen el acceso a cuartos en inmueble ocupados. Sin embargo, a la hora de arrojar luz sobre las experiencias de las personas, sus itinerarios y formas de socialización, es importante enmarcar estas prácticas en diversos escenarios de socialización que trascienden a la ocupación, como modalidad residencial histórica de nuestra sociedad.

Es en tal sentido que se considera que, en las trayectorias de las personas, las casas tomadas son una de las tantas modalidades de acceso al espacio urbano en la ciudad, son una opción más dentro de un mercado habitacional heterogéneo con ámbitos más o menos informales a través de los cuales las personas transitan. Si es que es posible realizar una distinción de carácter general con otro espacio residencial o establecer una barrera, en términos de Barth (1974 [1964]), con otra esfera económica, ésta es la que establece la garantía inmobiliaria frente al mercado formal de alquiler. En esa dirección se puede establecer la presencia de un mercado unificado formal que erige la barrera -vivenciada diariamente por las personas- de la garantía inmobiliaria (la garantía de confianza con respecto a la voluntad de pago, la estabilidad y la trayectoria de la persona) frente a un submercado con diversos grados de informalidad en donde quienes no tienen una garantía inmobiliaria construyen sus propias garantías: las relaciones personales, de afinidad y reciprocidad que habilitan el acceso a las modalidades residenciales informales de la ciudad.

En este mismo sentido autores como Smolka (2003) y Duhau (2003) han marcado la relación entre restricciones del mercado formal y desarrollo del mercado informal de la vivienda. Smolka discute con aquellos enfoques que asocian informalidad y pobreza para pensar el lugar de las regulaciones excesivas y elitistas del mercado habitacional que impone condiciones irrazonables en la ocupación del suelo urbano (Smolka 2003: 120).

Ampliando la perspectiva centrada en el mercado, el economista Pedro Abramo destaca la conjunción de tres lógicas de acceso a la tierra urbana y observa su funcionamiento en el caso de las favelas brasileras $(2003,1998)$. El autor señala que el acceso a la tierra urbana es concretado a través de tres lógicas de acción social, la lógica del Estado, la lógica del mercado y la lógica de la necesidad.

La lógica del Estado opera cuando las personas se subordinan a la decisión del poder público, quien asume la responsabilidad de definir la política que garantice cierto grado de bienestar social, y donde el Estado define la forma, la localización y el público que usufructúa la tierra urbana. La lógica del mercado define a éste como el mecanismo 
social que posibilita el encuentro entre los que desean consumir tierra urbana y los que se disponen a ofrecer el derecho de su uso o el bien en sí. Esta lógica puede asumir características institucionales diferentes, según el vínculo que el objeto transaccionado establezca con las normas jurídicas y urbanísticas de cada ciudad. Pueden encontrarse mercados cuyo objeto está inscrito en la normalidad jurídica y urbanística, los llamados mercados formales o que no se encuadren en esos requisitos normativos, los mercados informales (Abramo 1998). Finalmente, la lógica de la necesidad supone una acción condicionada por un estado de pobreza, por la incapacidad de suplir una necesidad a través del mercado, con recursos monetarios propios, o a través de programas sociales. En este sentido, la participación en organizaciones sociales y los vínculos trazados con actores políticos son algunas de las formas por medio de las cuales se logra acceder a recursos específicos.

Se toma este abordaje para pensar las modalidades de acceso a cuartos en inmuebles ocupados. También en el análisis se observa un proceso de mercantilización que, si bien pareciera primar en los ingresos de las personas a las casas, se plasma desigualmente en diversos ámbitos según domine, desde las percepciones de los propios actores, un criterio basado en la necesidad o un criterio de la ganancia (de apropiación privada de la renta urbana). Por otro lado, dos características específicas que se encuentran en los intercambios realizados en las casas tomadas son por un lado que la legitimidad de las transacciones es una cuestión disputada y sancionada por la ciudad circundante, tanto por sus vecinos como por actores institucionales del espacio barrial; y, por el otro, que el bien intercambiado es un bien con fecha de prescripción, el día de desalojo, y que sólo otorga un derecho precario al uso transitorio de un espacio ajeno.

A continuación se observan las trayectorias de un grupo de personas que desde mediados de la década de 1980 habitan en una casa tomada del barrio de Balvanera. Las experiencias de estas personas remiten a una forma específica de ocupación, motorizada por una necesidad y mediada por un actor político, en este caso referente político partidario barrial. La decisión de retratar esta ocupación desde una perspectiva etnográfica tiene como objetivo reconstruir la diversidad de situaciones y experiencias presentes en el campo de indagación, para luego poder dar cuenta de un conjunto de concepciones y categorías morales que en contextos sociales específicos ordenan discursivamente la diversidad existente.

\section{DE LA NECESIDAD AL CORAJE: EL ACCESO A CUARTOS EN UNA CASA TOMADA}

En el histórico barrio de Balvanera, sobre la Avenida Belgrano, treinta y cinco familias habitan en un edificio que pertenece a la Universidad de Buenos Aires (UBA). El edificio, abandonado al poco tiempo de ser construido, comenzó a ser ocupado a mediados de la década de 1980 por habitantes de hoteles y de otros inmuebles ocupados de la zona. Pasaron casi doce años antes de que recibieran la primera orden de desalojo y que asesorados por una organización social de la zona formaran una cooperativa de vivienda. El plan original consistía en comprar el inmueble para poder permanecer en el 
lugar y proyectar allí sus hogares. La UBA no aceptó la propuesta, pero suspendió el desalojo y realizó un acuerdo con sus ocupantes permitiéndoles permanecer en el lugar. A mediado del 2000 un grupo de vecinos retomó la propuesta de organizar la cooperativa para poder acceder a una vivienda definitiva y digna. Con esta meta en la mira, convocaron a parientes y vecinos a sumarse a su proyecto. La cooperativa Belgrano se enmarcó en un programa habitacional del Instituto de Vivienda del Gobierno de la Ciudad de Buenos Aires (GCBA): el programa Autogestión para el Desarrollo del Hábitat Popular.

El edificio consta de dos pisos. Cada uno abarca una amplia superficie, unos treinta metros separan la entrada de la última habitación de cada uno de los niveles. Las viviendas se erigieron sobre la estructura original compuesta por unos pocos ambientes de amplias dimensiones, un gran patio en el primer piso y un baño colectivo sin instalaciones ni conexiones realizadas. Con el transcurrir de los años, los habitantes fueron construyendo sus respectivas habitaciones dentro del edificio. Las habitaciones se ordenan a lo largo de dos angostos pasillos, la mayoría de las divisiones externas son de material y unas pocas son de «durlock», material que predomina en las divisiones internas. La mayoría de las habitaciones tienen cocina, instalada con su respectivo equipamiento, dos de ellas tienen baño y el resto de las unidades comparten dos baños situados en cada uno de los pisos. Sólo tres casas, ubicadas en el frente del primer piso y lindantes a un patio interno tienen ventilación al exterior, el resto de las unidades no tiene ventanas que permitan el ingreso de aire fresco y luz natural. La ventilación y la poca luz natural a la que acceden las personas provienen de la puerta de entrada, de la única ventana que da al frente del edificio, ubicada en el patio de una de las unidades, $\mathrm{y}$ de un pequeño patio interno ubicado al fondo del inmueble.

Los testimonios de los habitantes de la casa trazan distintas experiencias a lo largo del tiempo. A medida que la casa se fue poblando, ciertas personas se constituyeron en figuras reconocidas y un conjunto de normas internas se fueron delineando. Las formas en que las personas ingresaron al inmueble en diversos momentos constituye una pauta de cómo se fueron modificando y complejizando las modalidades acceso a esta tipología del hábitat popular. Según se desprende de los testimonios de los primeros habitantes, en un primer momento el ingreso se fundamentó casi exclusivamente en una lógica de necesidad y siguió los canales de las relaciones de reciprocidad presentes en el barrio.

Cuando clausuran el lugar, porque decían que no era habitable... Un grupo de personas toma una casa en Venezuela y Piedras, eran de otro hotel del barrio. Ellos nos dicen que vayamos para allá. Nos fuimos rápido porque ya no estaba quedando mucho lugar. La gente llegaba y elegía un lugar. El lugar estaba sin servicios. Tenías que ir con tu balde a planta baja para sacar agua. Era todo una mugre. Igual estaba bien, el lugar era más grande que la piecita. Duró poco, a los cuatro meses cayó la policía. Enseguida hicieron un censo de los que vivían en el lugar para ver si alguno tenía antecedentes, si éramos malos. Ahí en esa época mucha gente tomaba casas viejas... Nosotros no nos censamos, ese día no estábamos, así que no nos dejaron quedarnos. 
P: ¿Por qué se tenían que ir?

Porque no estábamos en la lista del juzgado. La gente se enojó con nosotros, porque ¡nos querían! Y no nos podíamos quedar.

Cuando estábamos ahí vino el hermano de mi ex. Vino de Mendoza con la familia, tampoco tenían nada, vivían como nosotros en un ranchito. Él había conocido a un hombre que andaba en política, que estaba con gente que había abierto una casa en Venezuela. Le dijo que había una casa en Belgrano, que podía ir pero que no llevará más gente. Fuimos nosotros. Agarramos una pieza grande y la dividimos con una cortina y un ropero. Creo que en la planta baja vivía sólo un señor.

P: ¿Les cobraron algo por entrar?

A: No, no se cobraba nada (Amanda).

Cuando llegué había 17 familias, todavía no se había construido tanto como ahora, yo dormía al aire libre en la terraza, después me dieron la pieza chiquita del fondo, pero era terrible, era muy chiquito y estaba al lado del baño. Después por mi cuenta decidí construir acá, esto era un pasillo amplio yo separe una parte y de a poco fui construyendo (Fermín).

Cuando vinimos a conocer. Era un edificio pelado, no había nada, cuando lo vi dije « $\mathrm{Ni}$ loca vivo acá!». [...] Vivían unas pocas personas al descampado, en espacios abiertos, todavía no habían hecho las separaciones. Primero paramos en la casa del hermano de mi marido, estábamos muy apretados, era muy incómodo. En junio mi marido cobró un trabajo, con eso compramos listones de madera y pedimos una reunión con los vecinos para pedir permiso para armar una pieza en la parte de adelante. Dijeron que no había problema, que ahí estaba desocupado. Y bueno, cercamos la parte de la cocina y la habitación, lo que es el patio, antes era el pasillo del edificio (Blanca).

Los hermanos Flores fueron unos de los primeros habitantes del edificio en la avenida Belgrano. Ellos son los respectivos esposos de Amanda, Blanca y de la hermana de Fermín, Beatriz. Los tres provienen de la localidad de Plumerillo en la provincia de Mendoza y llegaron a Buenos Aires a principios de la década de 1980 buscando mejores condiciones de vida. Luego de vivir durante los primeros meses en Buenos Aires en hoteles y en otras casas tomadas, un político de la zona les sugirió que fueran al edificio de la calle Belgrano. Aún no había construcciones en el lugar, cada uno de los que llegaba se acomodaba dónde podía y a medida que iban teniendo algún ingreso, construía su casa. No les cobraron entrada, según explicaran luego, porque en el inmueble no había nada para vender. Como sostuvo Blanca, el lugar había sido completamente desmontado. Asimismo, como expresan los testimonios citados, en la casa de la Av. Belgrano, ciertas cuestiones se acordaban.

Los primeros habitantes eran quienes les permitían a los recién llegados quedarse. No obstante, pasado un tiempo, los últimos podían solicitar a sus vecinos construir una o dos habitaciones en determinado lugar. La necesidad de un espacio era un argumento suficiente para realizar el pedido. Claramente las relaciones de parentesco, además de las relaciones de reciprocidad local, mediaban el acceso a la casa. El político les sugirió 
a los hermanos que no llevaran a nadie más. Tiempo después el criterio fue aceptar a los familiares y amigos de quienes residían en el inmueble, gente de confianza. Como alguna vez dijo Beatriz: «Siempre nos dimos el lujo de seleccionar al que entra que sea un conocido de alguno de acá». La afirmación de ella pone en evidencia que este lujo no se da en todas las casas, otros pueden ser los criterios de ingreso. Algunos años más tarde, se mudaron a la casa el ahijado de Fermín y dos hijas de Blanca. Aún hoy en día Fermín, su hermana y Blanca, trabajan con Pablo el político de Frente Grande, cercano a quien los hizo entrar y del partido que gobernó en la Ciudad hasta el año 2008.

Volviendo a los abordajes sobre pobreza urbana inaugurados por Lomnitz y Roberts, a su consideración de las redes territoriales de reciprocidad en la configuración de la economía informal (Roberts 1978) de los marginados (Lomnitz 1975), además de sus relecturas en el marco de análisis concretos: las villas de la CABA (Cravino 2006, 2009), de Río de Janeiro y San Pablo (Abramo 2003), es inevitable acudir a la categoría de confianza, para pensar estos primeros ingresos a Belgrano. La historia de estos hermanos tan involucrados en los primeros años de esta ocupación muestra que el principal criterio de ingreso en los orígenes de la casa se asentó en la confianza como categoría de conocimiento interpersonal y de cercanía social. La confianza se manifestaba en dos sentidos: un sentido cognitivo, tal como fue definido por Simmel (2002 [1917]), el conocimiento intersubjetivo producido a partir de la información de carácter personal, que intermedia entre el conocimiento y la ignorancia respecto de una persona. Pero también en el sentido ampliado, esbozado por Lomnitz (1975) como la cercanía psicosocial real entre individuos que comparten los rasgos de la cercanía social, la cercanía física y la igualdad económica. Nuevamente, la necesidad económica fundamentaba el ingreso a una casa ajena. Se verá que la necesidad económica, además de ser un criterio, es un valor normativo que observa la conducta de los habitantes de casas tomadas y que opera diferencialmente en relación a diversas prácticas (la compra de un cuarto, su venta, su uso con una funcionalidad distinta a la habitacional). Retomaremos este punto en el siguiente apartado.

Los hermanos Flores no fueron los primeros en entrar a la casa. El mayor sabía que había un edificio abandonado en el barrio pero no quería entrar primero, recién lo hizo después que el político se lo sugirió y cuando observó que ya había gente viviendo allí. Abrir una casa abandonada entraña un riesgo, sin olvidar que hoy la ley lo concibe como un delito que puede ser penado con hasta tres años de prisión. Por eso, como sostiene Fermín, hay que tener coraje para abrir una casa.

Mi vecina conocía al primer señor que vino a vivir acá. En realidad nos contaron que estaba antes que venga el señor pero mi marido no se animó a entrar solo, no quería ser el primero. Era mejor esperar (Beatriz).

El primero que vino fue Ramón, estaba en la cooperativa, hace años se fue. Vino con coraje y se metió, no sé qué será de él.

Bahh más que coraje es la necesidad que te de coraje, por lo menos antes era así, porque también es cierto hoy hay gente que se dedica a abrir casas, ahí es sólo coraje, no hay necesidad, pero igual empiezan por la necesidad, después se hacen pillos (Fermín). 
Los testimonios dan cuenta de los sentidos que asoman en relación al acto de abrir una casa. Hay que animarse, tener coraje para ser el primero. En otras oportunidades, otros vecinos del barrio comentaron que algún conocido les había propuesto abrir una casa, entrar, tomar la decisión extrema que les permitiera evadirse de la sangría que representaba el alquiler de una pieza de hotel. «Hay que ser corajudo», «qué te vas a animar» solían ser las respuestas. De hecho pocos se animaban, además de tener la mayoría una opinión desfavorable en relación a la ocupación. Retomando los testimonios, Fermín sostiene que el coraje suele ser alimentado por la necesidad pero a veces deviene en negocio y pillaje. En su testimonio, traza claramente dos modalidades de ocupación, una impulsada por la necesidad y otra por el negocio de quienes se dedican a abrir casas. Ambas lógicas no son necesariamente independientes, el negocio puede suceder a la necesidad y/o puede ser alimentado por ésta, por la necesidad de un techo de otra persona, de alguien que no tiene el coraje para abrir una casa.

Las modalidades de venta, de ingreso y en ciertos casos de alquiler varían en diversos contextos y son evaluadas desde valores morales asociados a la lógica del negocio y de la necesidad. Al principio de la investigación solía perderme en los criterios relativos a los precios, modalidades de ingreso y lejos de la actitud de un buen antropólogo no podía evitar juzgar ciertos criterios. Paso un tiempo antes de que pudiera comprenderlos. En una oportunidad Beatriz explicaba acerca de una casa tomada, ubicada en frente a la casa en que vivía.

Acá enfrente también hay una casa tomada, es de unos salteños, ahí se paga entrada, cuando se mudó el hijo de la de arriba cobraban quinientos, algo así.

P: ¡Quinientos, es caro! No sé, no me parece.

Pero paga por una sola vez, cuando entran, lo paga y se quedan hasta que los echan, hasta el desalojo (Beatriz).

En los testimonios de los habitantes de Belgrano, eran corrientes las mudanzas de la casa de los Salteños a Belgrano y viceversa. En la primera casa, quienes cobraban entrada eran quienes la habían abierto y subdividido. Del testimonio de Beatriz se desprende que lo que se cobra es el ingreso a una casa que ya fue ocupada por alguien y el uso de un espacio que fue subdivido y, a veces, construido por quien lo habitó anteriormente. El pago del ingreso otorga un derecho transitorio en relación a la habitación y a los espacios comunes pero no otorga derecho en relación al inmueble. Cuando llega el día del desalojo te echan. La ocupación fundamenta su legitimidad en la necesidad de un techo. No obstante, no cuestiona la legitimidad oficial que le asigna a la propiedad privada el derecho primero, la ocupación es transitoria, el cuarto «te lo venden hasta que te echan». Como me explicó en una oportunidad un integrante de una organización.

Ellos te cobran un ingreso. Te dicen que no saben cuánto tiempo podés estar ahí, puede ser un mes, tres meses, un año. Yo entré en un edificio en Avenida de Mayo. Puse 500 pesos. Quince días duró. Nos desalojaron a todos. ¡Nunca más! (Florencio). 
De la misma manera que el pago no otorga ningún derecho en relación al inmueble tampoco lo hace en relación al barrio y de cara a los vecinos inquilinos y propietarios. Dado que si bien los habitantes de casas tomadas pagan el ingreso a una casa para vivir transitoriamente en ella, para ahorrar algo de plata durante ese tiempo, en sus interacciones con instituciones del barrio y con los vecinos ellos no dejan de ser interpelados como ocupantes. En tal sentido, la denominación de ocupante no suele ser asumida por quienes habitan en inmuebles tomados sino que es un mote por medio del cual la sociedad circundante los ancla a un espacio social específico. Y donde recaen el conjunto de intervenciones estatales, entre las cuales el desalojo es simplemente una. El siguiente testimonio da cuenta de las percepciones de los habitantes de casas tomadas, quienes definen procesualmente lo que institucionalmente es definido como un estado. Los habitantes de Belgrano consideran estar circunstancialmente viviendo en una casa tomada, sin por ello dejar de reconocer la mirada de quienes hacen de esa circunstancia una condición personal.

\begin{abstract}
Vivir en una casa tomada tiene sus cosas buenas y malas. Lo bueno es que no tenés gastos y eso te ayuda a ahorrar. Es mala porque tenés que conocer a determinada gente. Por otro lado, te obliga a organizarte, a esforzarte por conseguir cosas, es una lucha. Es difícil porque a veces vas a trabajar amanecido, porque se puede imponer la ley del más malo y para decir algo tenés que ser duro. $\mathrm{Y}$ otra cosa mala es que a mí pueden venir a decirme que no pago el alquiler y que no soy el dueño y que no me puedo quejar. Es distinto para los vecinos del edificio de al lado, ellos pueden venir a reclamarte si tirás la basura en su puerta, pero nosotros no podemos decir nada si nos tiran basura a nosotros. También pasa que viene la policía y ya nos mete a todos en la misma bolsa, o vos vas a la comisaría a hacer una denuncia, te preguntan de dónde sos, si les decís, tu denuncia ya no tiene valor (Fermín).
\end{abstract}

Si bien el acceso a un inmueble ocupado posibilita tener a ciertas externalidades de los barrios en los que se ubican, en términos de oportunidades de empleo, acceso a instituciones públicas, medios de transporte e infraestructura urbana de calidad, los habitantes de inmuebles ocupados reconocen en la opinión de sus vecinos la negación del derecho a estos mismos recursos. De ahí que en su desplazamiento por la ciudad prime una estrategia tendiente a invisibilizar su condición residencial. La mayoría de los entrevistados destacaba que la opción de la casa tomada era una opción transitoria. El tiempo de residencia era el tiempo suficiente para juntar algo de plata que les permitiera proyectar una salida un poco más estable. Otras veces era el tiempo de educación de los hijos o de actividad laboral intensa. Desde esa misma perspectiva, la permanencia extendida en el tiempo en una casa tomada, la intención de permanecer en ella o la circulación de una persona por diversas casas ocupadas era negativamente evaluada. Quienes se mudan de una casa tomada a otra son «quien están acostumbrados a vivir gratis», quienes hicieron de la necesidad una forma de vida, son los ocupantes ahora vislumbrados desde una categoría moral que marca sus prácticas valorativamente. Los habitantes de la casa de Belgrano comparten estas valorizaciones sobre sus vecinos ocupantes. 


\section{II.1. Tiempo, autoridad y valores morales al interior de Belgrano}

La elección de comprar o alquilar un cuarto en una casa tomada se fundamentaba en la imposibilidad de afrontar un alquiler en el mercado formal por no tener recursos suficientes o por tenerlos pero no contar con una garantía inmobiliaria. Otras veces la elección radicaba en una ventaja comparativa en relación a hoteles y pensiones: la posibilidad de conservar pertenencias.

No nos podíamos ir a un hotel porque teníamos todas las cosas de la casa, los muebles, la heladera y no podes llevarlas al hotel. ¡Teníamos al perro, al gato!

En tal sentido, como señala Abramo para el caso de las favelas brasileras (2003), en la opción por el acceso a un cuarto en una casa tomada (en comparación a modalidades como los hoteles) también está presente su consideración como un ámbito que posibilita cierta acumulación de bienes durables. Aunque en este caso predomine la incertidumbre frente al desalojo, eso no quita que en lo inmediato la casa tomada pueda ser más estable que la opción por el hotel. El paso del tiempo aumenta la seguridad en relación a la permanencia de la casa y puede redefinir las estrategias habitacionales en torno a ella. La realización de mejoras edilicias y el pago de servicios en algunos casos pueden fortalecer los sentidos de pertenencia y, a largo plazo, en el contexto de un juicio de desalojo, operan como testimonio del tiempo vivido, de su uso residencial y de ciertos derechos adquiridos. En tal sentido, considero que, como sostuvo Abramo, también se puede pensar en la estrategia de acceso a una casa tomada y pasado un tiempo la inversión y la permanencia en ella, como una estrategia polifuncional orientada a mejorar las condiciones de vida familiares en términos intertemporales, como para consolidar en el tiempo la forma no mercantil (Abramo 2003) de la ocupación. Nuevamente, esta estrategia se va definiendo con el correr del tiempo, en los casos en los que no hay propietario reivindicando su título o en los que, como en el caso de Belgrano, éste establece un acuerdo con los habitantes del lugar. Aun así en todos los casos el paso del tiempo es un factor definitorio en el devenir de las estrategias residenciales de los ocupantes.

El hecho de residir en una casa tomada no se traduce en la definición de un estatus o identidad social. La mayoría de los habitantes de Belgrano consideraban estar circunstancialmente en el lugar, por eso mismo, un grupo de habitantes había creado una cooperativa de vivienda con el propósito de proyectar una salida definitiva. Aun así, esto no impedía que fueran catalogados como ocupantes por las instituciones del barrio.

La policía tiene marcadas a las casas tomadas. Marcó a Belgrano, a una casa acá a dos cuadras, a la casa de los peruanos, antes no podías ir a la comisaría porque te tenían marcado (Valeria).

Con el paso del tiempo, la consolidación de la cooperativa contribuyó a revertir el peso del estigma y a constituir a ciertas personalidades como interlocutoras de diversos 
actores institucionales del barrio. El nombre de la organización dentro de la cual se enmarcan sus integrantes y a la cual erigen como referente de su propia práctica social les otorgó autoridad en lo que hace a la organización de la vida diaria en la casa y jerarquizó su lugar en el barrio. No independientemente de esto último, el hecho de que los socios más antiguos de la cooperativa (los primeros habitantes) se hayan organizado para sacar de la casa a un grupo de jóvenes que vendían droga en la zona afianzó el respeto ganado en el barrio. Tal como les gusta destacar a los habitantes de la casa, ahora la policía «distingue» a Belgrano de las otras casas tomadas del barrio.

Blanca y Beatriz, por su antigüedad en la casa, por sus respectivos roles en la cooperativa y por sus vínculos con políticos del barrio, se han constituido en voces autorizadas respecto a la vida y organización del lugar. Los habitantes de cada uno de los pisos reconocen en ellas a las responsables del edificio frente a referentes e instituciones barriales. Son quienes organizan las reuniones cuando hay que tratar ciertos temas y a quienes acuden las personas para resolver determinados conflictos. Son quienes manejan información sobre la situación judicial de la casa y programas sociales y recursos estatales disponibles. Se espera de ellas que organicen día a día la vida de la casa.

Beatriz es la que lidera arriba. Ella tiene que hablar con los que están construyendo arriba, ella es la que puede. Ahora también construyó el que está al lado de Fermín, no puede hacerlo porque nos saca la poca luz que entra, ahí la que tiene que hablar es Blanca, ella es la más antigua. Para estas cosas lo que pesa es la antigüedad, yo estoy hace tres años; mucho no puedo decir. Y como no sos dueño tampoco podés decir nada, a ver si después te agarran las cosas y te sacan (Valeria).

Las relaciones sociales en la casa siguen un modelo en el cual el tiempo de residencia establecía un poder diferencial entre los recién llegados y los habitantes originales. Al interior de la casa las relaciones entre los recién arribados y los primeros habitantes se ordenaban según una figuración en la cual los segundos fundamentaban su autoridad en la adjudicación de un conjunto de valores morales que legitimaban y normaban la vida dentro de la casa. El tiempo de residencia en el inmueble y el consecuente grado de organización alcanzado entre los primeros habitantes les otorgaba una posición de poder en el marco de las relaciones de interdependencia vigentes en este ámbito particular. Esta modalidad relacional nos remite a un tipo de relación de poder que encuentra en la antigüedad residencial su fuente primera. Scotson y Elías (1994) denominaron a esta figuración como una relación entre establecidos y outsiders. En Belgrano, se encuentra que la autoridad de ciertas personalidades se asentaba en un principio de antigüedad que tomaba cuerpo en valores morales como los de «la buena convivencia», la igualdad de las carencias y la legitimidad de la necesidad, que eran reivindicados como rasgos característicos de los primeros años de ocupación, en contraste con el tiempo presente. En el marco de esta figuración que la necesidad -como fundamento de ocupación- y su contrapartida, la venta de una pieza desde 
una lógica mercantil, se constituyen en valores morales desde los cuales se evalúan las prácticas de los ocupantes.

Esta figuración de poder no se limita a la vida en los inmuebles ocupados sino que comprende relaciones de interdependencia que trascienden este espacio, con actores estatales del espacio barrial, con organizaciones sociales, entre otros actores sociales (compañeros de trabajo y patrones, familiares, vecinos). De hecho, por fuera de este espacio los establecidos serán los outsiders de la ciudad y paradójicamente replicarán la relación de poder que los subordina al interior de su ámbito residencial. Se considera que la figuración de poder establecidos-outsiders opera aquí escalarmente ejemplificando la fragmentación social del espacio urbano porteño. Mientras que en la casa los establecidos son una voz autorizada que encarna la legitimidad de la residencia en un inmueble ocupado, puertas afuera se saben outsiders de la ciudad. Y paradójicamente los atributos negativos asociados a su condición, la «delincuencia», la «vagancia» y el «abandono», son materia de estigmatización de los establecidos a los outsiders internos. Lo último se ponía en evidencia en las reuniones de la cooperativa de vivienda donde los socios que no habitaban en casas tomadas sospechaban de la posibilidad y voluntad de pago de la cuota del crédito de la cooperativa y de la convivencia con los familiares ocupantes de los socios de la cooperativa. La diversificación y la complejidad de la figuración establecidos-outsiders en un escenario heterogéneo y desigual (distinto al estudiado por Scotson y Elías) no quiebra las relaciones de interdependencia trazadas en el ámbito barrial y la reproducción de la estigmatización de los sectores hegemónicos en diversas escalas de inserción social (el contexto político local, el espacio barrial, una casa tomada).

\section{II.2. Comprar y vender piezas}

Vanesa y Horacio se mudaron a Belgrano en el 2001. Para ese entonces la casa se había poblado y los espacios abiertos habían sido desplazados por las construcciones realizadas por cada una de las familias. Asimismo, como consecuencia de la constante movilidad residencial de los habitantes, algunos cuartos se habían desocupado y vuelto a ocupar, ahora con nuevos criterios. Por ese entonces, Belgrano contenía unidades residenciales de diversos tamaños, materiales y estilos. Cuando Valeria y Horacio tuvieron que dejar la portería en la que vivían, Fermín les comentó que uno de sus vecinos se volvía a Misiones y vendía su pieza. La pareja tenía que dejar su casa en marzo y el hombre se iba en diciembre, así que primero se mudaron transitoriamente a la casa tomada de los salteños.

Fuimos a la casa de acá enfrente, la de los salteños. Ellos entraron, agarraron unas piezas para ellos y vendieron las otras, después se volvieron a Salta. El lugar era un desastre, una mafia. Los salteños nos vendieron el departamento por 1500 pesos. Ellos habían desalojado a los que vivían ahí, si no les gustabas te rajaban. En cuanto se desocupó acá nos vinimos. Acá vendían por 2500 pesos, así que vendimos el lugar de enfrente por 1500 
y juntamos un poco más de plata. Cuando Fermín nos dijo de este lugar no estábamos muy seguros pero sabíamos del acuerdo con la facultad, aunque nunca es seguro (Valeria).

Valeria y Horacio ingresaron a Belgrano comprando un cuarto. No obstante, en su testimonio, realizan una distinción con los salteños. La diferencia es que si bien ellos compraron su inmueble en ambos lugares, los salteños se manejaban desde una lógica de negocios; ellos abrieron una casa para regentear y vender el uso de cuartos, transitoriamente, dado que se abogaba el derecho a desalojar.

Del testimonio de Valeria se desprende la existencia de un submercado que parece operar en las casas tomadas. Las prácticas entabladas a su interior son valorizadas diferencialmente por los actores según se fundamenten en la existencia de una necesidad o sean motorizadas por un interés meramente económico. En términos generales, la compra de un cuarto para vivir suele ser una práctica considerada legítima en contraposición a la ocupación para su venta. Aun así, la venta también es atravesada por este doble criterio y suele ser socialmente aceptada cuando se fundamenta en la necesidad de dinero para fines de consumo social. Es común que un cuarto sea vendido ante la necesidad de obtener dinero para viajar, mudarse o para el tratamiento médico de algún integrante de la familia. La legitimidad de la transacción económica también radica en el bien ofertado: lo que se vende es lo construido, la inversión realizada en la propia casa.

En la base de la preferencia por Belgrano, se encontraba el conocimiento previo de sus habitantes de la relativa estabilidad que materializaba el contrato firmado con la UBA. La pieza de Belgrano era más cara que la de la casa de los salteños, sin embargo, como luego me explicaron los habitantes de la casa, lo que estaba en venta era la construcción realizada por el habitante anterior, en este caso dos habitaciones grandes con una cocina. En la duda que Valeria expresa en relación a la compra y mudanza a Belgrano aparece como factor decisivo la relativa estabilidad del lugar. En cierto modo el acuerdo operaba como factor de anticipación, como expectativa de seguridad (Abramo 1998) a la hora de tomar la decisión de comprar el cuarto. Otro aspecto que en ciertas oportunidades puede aparecer como factor de anticipación a la hora de decidirse por pagar un cuarto en una casa tomada es la política habitacional para situaciones de desalojo, puntualmente los subsidios habitacionales ${ }^{2}$ otorgados por el GCBA.

A la casa de los salteños la desalojaron, en diciembre los sacaron a todos. Un señor de acá estaba viviendo allá, le dieron 1800 y con eso compró en otra casa. Todos se fueron por su cuenta con los 1800. Con los desalojos funciona así, primero te ofrecen 1800, si no aceptas te sacan a la fuerza (Valeria).

2. Por medio del programa AFSC el GCBA otorga subsidios mensuales de 200 dólares mensuales (1000 pesos) a familias desalojadas de inmuebles de la ciudad. 
Si no hay una organización mediando, difícilmente las familias resistirán el desalojo. La expectativa en relación al subsidio puede incidir en la decisión de vender un cuarto y en la modalidad de venta.

A diferencia de los primeros años quienes hoy en día entran en Belgrano compran piezas. Sin embargo, según sostienen los habitantes lo que se compra y o vende es el espacio construido, el derecho a su uso. Según sostienen los habitantes de Belgrano, quienes venden cuartos venden un espacio por ellos construido. Se observa que un conjunto de reglas pautan tanto la construcción como la venta de las habitaciones construidas.

Acá hice unas cuantas mejoras. Los vecinos me decían que para qué construía tanto si igual nos iban a desalojar. Yo construía porque quería vivir mejor. Y pensaba que si yo tengo que alquilar tengo que pagar 500 o más, bueno prefiero ponerlo acá. Al principio los otros tenían separaciones de cartón, ahora es todo de material. [...] Y acá se vende, vendemos nuestra casa porque la construimos, pusimos esfuerzo, es moralmente correcto (Fermín).

Tenemos reglas. Ahora no hay espacio para nada, unos chicos de abajo, que no tienen nada de lugar pidieron permiso para armar una habitación acá al lado y les dijimos que no porque iban a quitar el poco aire y luminosidad del edificio. Mientras hubo espacio siempre se pudo construir con la condición que no quitaran aire y luminosidad a todos los vecinos. Está bien que no todos lo respetan. Otra regla del edificio es que los cuartos no pueden venderse, lo único que se vende es el trabajo puesto, si se construyó se puede pero si no se hizo nada (Blanca).

Como señalan los testimonios, en Belgrano una norma interna establecía que lo que se vendía era lo invertido en la construcción de la pieza. El crecimiento del inmueble, por el incremento del número de habitantes y de los espacios construidos, junto a la movilidad residencial de los primeros demarcaba un mercado no sólo al interior de Belgrano sino de otras tantas casas ocupadas de la zona. Los habitantes de Belgrano estaban al tanto de la oferta de la casa de los salteños, como de otras tantas casas del barrio. Las lógicas de ingreso diferían en las distintas casas. Mientras que los salteños se guiaban por una lógica de ganancia (ocupaban piezas que luego vendían), en Belgrano se vendía lo que se construía. Si bien otros habitantes no respetaban esta regla, eran objeto de murmuraciones y críticas de los habitantes más antiguos. Más allá de las diferencias en lo que hace a la venta de cuartos en una y otra casa, en lo que respecta al consumo lo que prima es el valor de uso del bien intercambiado; quien compra un cuarto, lo hace para habitarlo. Una vez más es el reconocimiento de una necesidad lo que legitima la compra de un inmueble y su posesión. Quien no hace uso de él corre el riesgo de ser sacado de la casa. En cierto modo, en Belgrano sigue prevaleciendo el criterio de la confianza a la hora de comprar o vender cuartos, por lo menos en su componente de cercanía social e igualdad en la condición de pobreza, igualdad implícita en la posibilidad de establecer una relación de reciprocidad. 
Hace poco se fueron un matrimonio chileno y otro paraguayo. Los dos vendieron sus cuartos. Los paraguayos se lo dieron unos parientes y los chilenos a una pareja, que, ¡si los vieras!!! Trabajaban en un banco, estaban muy bien. Enseguida armamos una reunión porque la hija de Susana estaba ajustadísima en una pieza chiquitísima y el acuerdo era que no se le podía vender piezas a la gente de afuera. Primero, a los de adentro. Así que nos juntamos y la cabecilla del piso de abajo dijo que habían comprado sin consultar, y que el edificio tiene reglas, que no se puede vender piezas sin consultar. Los paraguayos dijeron que no tenían a dónde ir, los del banco se fueron a la mañana siguiente (Blanca).

Los empleados eran gente que estaba muy bien, condición que los inhabilitaba para comprar una pieza en Belgrano, además de embarcarse luego en el conjunto de relaciones de reciprocidad e intercambios que aúnan las vidas de sus habitantes. Las modalidades de acceso a estas casas tomadas, las relaciones sociales trazadas a su interior y la presencia de una normativa que regula el intercambio de cuartos dan cuenta de la presencia de un submercado habitacional que se perfila en este espacio particular. La caracterización desarrollada por Cravino (2006) para el mercado informal de las villas de Buenos Aires se observa en las casas tomadas de la ciudad: la compra y venta de cuartos son parte de un conjunto de transacciones inmobiliarias mercantilizadas que claramente no están ajustadas a normas legales y urbanas y cuyos actores interactúan por fuera de las regulaciones económicas, legales y constituyen un entramado aparte del mercado formal. Si bien desde el punto de vista legal su carácter informal salta a la vista, se considera central pensar cómo se constituye la legitimidad entre los agentes involucrados.

Quienes ocupan inmuebles (y/o compran cuartos) actúan en el margen del campo social que delimita el mercado habitacional, se mueven en sus grietas, constituyendo legitimidades alternativas. En este caso, inmuebles desocupados, abandonados por sus dueños, dejados a la espera de momentos más rentables desde una lógica especulativa, son el campo de incidencia de estas personas. Como ya se mencionó son parte de un campo inestable, transitorio, que no es cuestionado en su legitimidad última: el del valor máximo de la propiedad que pregona la legislación estatal. Más allá de los márgenes de la legalidad, se considera que su característica central es justamente aquella destacada por Cravino (2006) para las villas porteñas. La misma se desarrolla en el marco de relaciones que surgieron como no mercantilizadas (desde la lógica del consumo, más que la del intercambio) y no logra desincrustrarse totalmente de esas relaciones. Al igual que observó la autora en las villas, en el submercado de compra de habitaciones no hay mediadores y las transacciones se realizan en el marco de relaciones de afinidad. Por otro lado, su legitimidad se funda en la lógica del consumo y de la necesidad por sobre la de la ganancia. Por más que la segunda pueda operar en determinados ámbitos, cuando así sucede esta suele ser objeto de evaluaciones morales.

Es precisamente la incrustación de este mercado en el conjunto de relaciones personalizadas lo que le aporta su particularidad y explica la diversidad de criterios puestos en juego en distintos espacios. En tal sentido, las normas y valores que rigen las prácticas de acceso a cuartos no son necesariamente internos a la esfera de las casas 
tomadas sino que provienen de esferas más amplias en las que transcurre la vida de las personas. La diversidad de criterios en torno a la venta de cuartos en Belgrano y en la casa de los Salteños es un ejemplo de ello.

Se considera que la principal diferencia entre el submercado al que refiere Cravino (2006) y el de venta de cuartos en casas tomadas radica en las formas en que cada uno construye su legitimidad de cara al entramado urbano más amplio. Mientras las villas se han constituido en un espacio de interpelación de los organismos oficiales y las situaciones de tenencia, aunque son precarias, no dejan de ser reconocidas por la autoridad estatal, esto no sucede en las casas tomadas. La legitimidad de los intercambios de este mercado es reconocida tan sólo al interior de las casas tomadas y de las organizaciones sociales involucradas en este espacio. Esta legitimidad refiere a un estado transitorio, de emergencia, de pasaje hacia alguna otra condición social. Mientras se vive en una casa tomada se debe hacer algo, ahorrar, organizarse, armar una cooperativa, demostrar que se aspira a otra cosa. A lo sumo, como consecuencia del tiempo habitado en un inmueble ocupado, sobre todo cuando es público, las familias adquieren legitimidad como habitantes del barrio, como usuarias de sus instituciones, desde un repertorio de roles que excluye su estatus habitacional. Es desde ese lugar, que llegado el día del desalojo pueden reivindicar su condición de ciudadanos y exigirle al Estado ser asistidos frente a un derecho habitacional vulnerado.

\section{CONSIDERACIONES FINALES: LA ESFERA RESIDENCIAL DE LOS «POBRES URBANOS»}

El análisis de las heterogéneas prácticas económicas de acceso a cuartos de casas tomadas permite entender que el conjunto de normas que rigen los intercambios no son intrínsecas a este submercado sino que se nutren de esferas sociales de más largo alcance en las que se insertan las personas en su vida diaria. Por ello, es preciso situar al conjunto de prácticas y pautas sociales involucradas en las modalidades de ingreso a una casa tomada dentro de la esfera social específica de las opciones residenciales populares, informales y semiinformales, del espacio urbano porteño. Se remite al concepto de Barth (1974), quien destaca que las barreras entre esferas no están dadas por una pauta de intercambio directo, como en el caso del mercado, sino por la pauta de circulación de los bienes, la conversión de su valor en diversos espacios sociales, además de los valores morales y, agregamos, las concepciones relativas al intercambio y lo intercambiado.

En el caso aquí analizado se identifican como elementos claves en la conformación de la esfera habitacional de quienes no cuentan con una garantía los límites establecidos por el mercado (esfera habitacional) formal -la posesión de una garantía inmobiliaria-, el conjunto de relaciones personalizadas que determinan la búsqueda de una opción habitacional por fuera del mercado formal y los valores morales constituidos en el seno de las figuraciones propias de esta esfera y del entramado institucional circundante. Finalmente, destacamos las heterogéneas normas que los habitantes de casas tomadas 
han elaborado a lo largo de los años, en el marco de figuraciones sociales cuyas legitimidades afloran en los márgenes de nuestra ciudad.

\section{BIBLIOGRAFÍA}

ABRAMO, Pedro. La ciudad Caleidoscópica-coordinación especial y convención urbana- una perspectiva heterodoxa de la economía urbana. Bogotá: Universidad Externado de Colombia, 1998: 125-196.

ABRAMo, Pedro. A cidadde da informalidade. O desafio das ciudades latinoamericanas. Río de Janeiro: Livraria Sette Letras, 2003.

BARTH, Fredrik. Esferas económicas en Darfur. En FIRTH, Raymond (comp.). Temas de Antropología Económica. México: Fondo de Cultura Económica, 1974: 150-174.

Clivchevsky, Nora. Construcción y administración de la ciudad latinoamericana. Buenos Aires: Grupo Editor Latinoamericano, 1990.

CRAVINO, Cristina. Vivir en la villa. Relatos, trayectorias y estrategias habitacionales. Buenos Aires: Universidad de General Sarmiento, 2003: 1-23.

CRAVINO, Cristina. Las villas de la ciudad. Mercado e informalidad urbana. Buenos Aires: Universidad de General Sarmiento, 2006: 1-276.

ELÍAS, Norbert. Compromiso y distanciamiento. Buenos Aires, 2002 (1983).

ELÍAS, Norbert y SCTOSON, John. Os estabelecidos e os outsiders. Sociologia das relacoes de poder a partir de uma pequena comunidade. Rio de Janeiro: Jorge Zahar Editor, 1994 (1990).

PITT-RIVERS, Julian. Grazalema: un pueblo de la Sierra. Madrid: Editorial Alianza, 1989.

ROBERTS, Bryan. Cities of peasants. Explorations in urban analysis. London: Edward Arnold. 1994.

SimMEL, Georg. Cuestiones fundamentales de sociología. Buenos Aires: Gedisa, 2002 (1974).

SMOLKA, O. Martim. Regularización de la ocupación del suelo urbano: La solución que es parte del problema, el problema que es parte de la solución. En ABRAMO, Pedro. La ciudad de la informalidad. El desafío de las ciudades latinoamericanas. Río de Janeiro: Ed. Sette Letras, 2003: 119-139. 